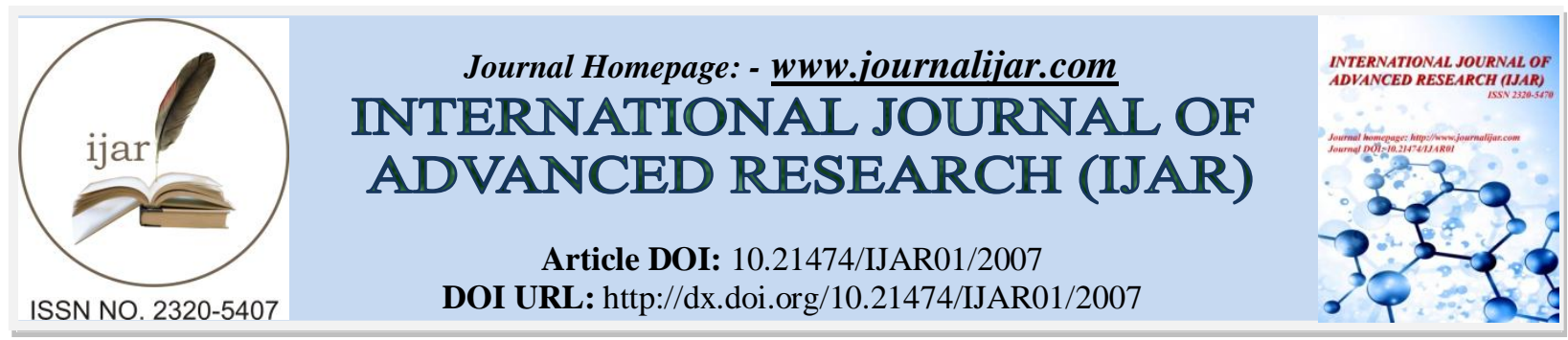

RESEARCH ARTICLE

\title{
AN EVALUATION FOR EMPLOYEES PERFORMANCE AND SECURITY AND CAREER ADVANCEMENT A READING INTO JORDANIAN CIVIL SERVICE SYSTEM NO.82 FOR 2013 AND ITS AMENDMENTS.
}

Dr. Issa Abedlkarim Manna' Aladwan.

Head of the Foreign Media Department The Senate- Jordan.

\section{Manuscript Info}

Manuscript History

Received: 15 September 2016

Final Accepted: 25 October 2016

Published: October 2016

Key words:-

Evaluation, Employees Performance, Security, Career Advancement Jordan

\section{Abstract}

The Study aimed to detect the reflections of performance reports on the security and career advancement of the employees of Civil Service throughout the provisions of the civil service system items NO 28 for 2013 and its amendments. And to answer the inquires of the study the researcher has used the Deductive and Inductive approach as well as the Fundamentalism approach which the provisions, the general rules and the criteria aiming to derive the rules and to extract Principles and Evidences. The importance of the study comes from being the only of its kind and that it is extensive in reviewing performance reports on Civil Service, as well as its role in the career security throughout the provision of the system's items. The Study limitations are representative in human limitations where theoretically it has included all employees in Civil Service, objective limitations where the study has addressed security and career advancement philosophy highlighted by performance reports according to the system. The study resulted in that the Civil Service System NO. 82 for 2013 and its amendments, despite of some simple gaps, is capable of establishing career security among employees, and that the instructions of performance management and evaluation is capable of figuring out strength and weakness points in employees performance, and to achieve justice and equality among them, as well as meeting their training needs if it was applied fairly and objectively.The study has recommended to evaluate employee's performance and achievements regardless their levels and job titles objectively and professionally, and to apply reward and punishment approach among all fairly and with no exceptions, and also to activate the role of liaison officers and Civil Service Bureau representatives who are available in all the governmental initiations.

Copy Right, IJAR, 2016,. All rights reserved.

\section{Introduction:-}

The importance of the performance evaluation process, that it is used by human resources administration, comes from its comprehensively to all administrative levels in the institution beginning with the higher management and ending with employees in different departments and administrative units, and it is considered to be successful to notice the positive and negative points for the employees and to recognize their strength and weakness points in 
his performance as well.Accordingly, a plan to improve performance and encourage and enable the employees to improve their strength points is being settled, while training strategies to fix and remove their weakness points are credited. Evaluation also enables the institution to judge the accuracy of the procedures and the programs that have been credited, whether it were hiring procedures and attracting experienced people, or it were training and enhancement programs and to follow up with its staff. And the importance of performance evaluation is also so obvious in achieving justice and equality among employees and to spread the spirit of enthusiasm and competition among them, and to figure out future competencies, and to determine the basis of rewards, salaries increments and promotions. Hence, performance evaluation style should be formal and systematic to create trust for the employee and to give an impression of the seriousness of the institution in which he works for and that it is interested in his work which increase his loyalty to his institution so that he will do his best to achieve its goals and work with more enthusiasm . It is a must to submit the performance evaluation to the strategic level in the institution, as this considered to be of high importance, as the strategic plans in the situation is associated with many variables, and the most important one is that which is related to human resources in regard to their ability, efficiency and potential .

\section{Research Problem:-}

The research problem is representative in the ability of the legislations governing the performance evaluation of Civil Service employees to settle career advancement and security and that denial by many administration to the concept and the importance of career security for employees as it is considered to be a part of social security, as the employee should feel with the career security so that he can feel safe regarding his future in his work in which his family future lies in, and hence he can be creative in his achievement. And from this point, the problem of the research lies in the following main questions of the study:

1. Has the Civil Service System NO.82 for 2013 and its amendments to reveal the strength and weakness points in employee's performance and to achieve justice and equality among them and to meet their training needs as well?

2. Has performance evaluation and its management style been reflected on achieving more and more of career security, stability and advancement to the employees of Civil Service according to the provisions of the system ?

\section{Research Importance:-}

The importance of the study comes from being the only of its kind and that it is extensive in reviewing performance reports throughout the provision of the system's items, as well as its role in the career security throughout the provision of the system's items to Civil Service employees who are subjected to the system.

\section{The Study Objectives:-}

The research aims to the following:

- To identify performances evaluation in the general service and its management style.

- To show the reflections of performance evaluation on the career security and advancement.

\section{The Research Limitations:-}

The limitations of the research are represented in the following:

- Human limitations: The study has included, theoretically, all employees in Civil Service.

- Objective Limitations: The study has addressed security and career advancement philosophy highlighted by performance reports according to the system.

The Study Terminology:-

The Bureau:- Civil Service Bureau.

The System:- Civil Service System NO. 28 for 2013 and its amendments.

The Instructions:- Instructions of performance management and its evaluation for 2012 which is issued according to the system.

Civil Service:- The governmental institution and the state departments that are subjected to the system.

The Employee:- The person who is hired in the Civil Service according to the system.

The Annual Performance Evaluation Models:- TheRecords (Model) of annual performance evaluation and the final annual report. 


\section{The Literature:-}

Performance evaluation or revision is the way that employees are being evaluated using a systematic regular style according to descriptive reports for employee's performance and productivity inside institutions on the basis of pre-determined criteria and objectives by them aiming to increase the efficiency of the employees performance and to gain their love and loyalty achieving the highest possible levels of productivity.( AbdelMohsen,2013)

\section{The Importance of Performance Evaluation:-}

The basis in the performance evaluation process is to be continuous, organized and comprehensive to all employees to achieve the desired benefits from it whether for the institution or to the employees themselves, and the most importance are the below Al (Sideeqand Al Farsi 2015):

- Performance Evaluation is considered to be the basis in decisions making that are related to the general policies for salaries, rewards and incentives in a way that can achieve the principle of relative justice in regard to individuals' returns, and also the performance results is considered to be an objective basis to promotion and moving polices.

- Performance evaluation is considered to be a guide to determine the structure of employment in the institution, to determine the needed numbers of human resources, to make plans to the programs and policies of election and hiring, to estimate the validity of employment tests, and to reconsider the application of the principle of the right person in the right place according to his abilities and skills.

- It contributes in determining the training and developmental needs on the basis of their weakness sides in their performance.

- Performance evaluation helps in detecting potentials and abilities for individuals in order to make use of it in increasing the current level of performance.

\section{According to (Hanna, 2001) the benefits of evaluation are:-}

- $\quad$ Performance Evaluation results points out to how successful the used leadership and supervision patterns are.

- Performance Evaluation is considered to be a basis in the administrative development process whether it was related to organizational side for the institution or regarding the work itself.

- Performance Evaluation guarantees the continuous supervision on employees performance and contributes to increase the morale for individuals and to create an atmosphere in which human relation principles prevails in, and this is because employees can feel that all different policies and procedures for employment, distribution, training, portion and motivation is based on objective and fair basis which consolidates the relationships between employees themselves and with the management.( Rozlev,QATAMIN1995)

\section{Performance Evaluation Phases:-}

Performance Evaluation process goes in many phases which can be ordered as below:

The First Phase: The preparation before discussing performance valuation of the employee. : (Tawazi, 2015)

* choosing the right time and place.

* Setting performance averages.

* Reviewing the employee's performance and achievements for the previous year and comparing it with the current year.

* Setting the suitable solutions and procedures to fix the employee's previous weakness points.

* Preparing a plan to which the employee will be committed to stick to it through the next year and keep on following it up.

* Making sure that the taken notes are objective and not of personal views.

The Second Phase: Discussing the employee's performance evaluation.( Mustafa,2004)

* Mentioning positive points before the negative ones.

* Presenting the negative points in a way for improvement and mentioning ways to fix it, and what are the suitable alternatives and why these would be positive.

* When mentioning a particular behavior, it is necessarily to explain what happened, where, when and what was its effect on the work itself and on his colleagues. 
* A working plan for the employee to improve his performance and achieving the department's goals particularly and the whole company generally and following it up should be agreed on.

* Finishing up the discussion positively.

The Third Phase: Following up the Employee's Performance:-

To follow up on applying the agreed working plan continuously throughout the next year and fixing any flaws happening by then.

Performance Evaluation's Elements:-

Performance Evaluations is reflected on measuring the completed and achieved performance compared with the standard performance. And this leads us to the importance of having standards for performance that is suitable to measure the real performance apart from any bias or favoritism, and by this we can get quantitative and qualitative indicators to the real done performance.( Maher, 2014) sees that any system that system should contains elements that represent and explain itself. and performance evaluation system has many elements that represent it.( Ismail,2005)

And below are the right steps to conduct performance evaluation within institutions:-

* Performance evaluation system should begin with determining the goal of it, as this would determine other elements in this system and can affect it.

* Deterring the person in charge for the evaluation process.

- Stating the timing conducting the evaluation (Evaluation Timing) and this leads to more important steps in determining the standards or the elements in which the performance evaluation will be based on.

* Determining the evaluation method (style).

* Informing the subordinates with their performance evaluation results.

* Using the human resource for evaluation results in the different administrative jobs.

Uses of Performance Evaluation:-

Theinstitution can get benefits from the performance evaluation results of the employees in the following areas.

\section{Planning and re-planning strategically:-}

The modification and determination process of the strategic plans in the institution is linked to many variables, and the most important one is those related to human resources in regard to its ability, proficiency and potentials, also the possibility of investing the underlying potentials effectively, and so evaluation results are real indicators that provides the planner the needed info for the strategic planning which is compatible with what the human resources provide. (AbdAlBaqi 2007):

\section{Improving individuals:-}

Evaluation results are used in improving individuals in the institution through what it provides of information regarding the strength and weakness points of the employees, and helps the administration in crediting the right foundations in consolidating the strength points and designing training and developmental programs to control weakness points. ( Al-Hamoud,1994)

\section{Increasing the motives of the individuals:-}

The feedback for the employee regarding their performance is of high importance, because it is considered to be one of the main elements in job enrichment as employees are always looking for knowing the administration thoughts about them and their performance aiming to improve their self-performance.( Abu Sheikha,2000)

\section{Building a fair system of incentives:-}

Performance evaluation results helps in designing fair incentives systems, as there are basics in designing incentives that vary according to jobs and environmental variables that affect performance. Hence the performance evaluation system has to take into consideration these variables to provide valid information about the evaluation results which contribute in designing a fair incentive system based on skills.( Assaf,1998)

Performance Evaluation Methods:-

There are many ways for performance evaluation, and the most important are the following : 


\section{Evaluation Criteria List:-}

This method is the simplest one, most used, easiest method in designing and the simplest method to be used. It depends on determining the criteria of evaluation, determining the extent of availability of these criteria in individual's performance, and this is done through a scale that determines different levels for having the performance criteria. And by summing up the degrees of the evaluation, the result would be the evaluation level of the individual performance.( Adel,1985)

\section{Ordering employees:-}

Each direct manager orders his subordinates descendingly from the best to the worst, and here he doesn't depend on criteria, however, ordering them is based on the general performance (the whole performance) and then he comes up with a list of ordering employees according to their performance. This method is easy and simple but it suffers from the traditional problems of performance evaluation.( Hamzawy,1987)

\section{Comparing Employees:-}

In this method, each individual is given a chance to be compared with rest of individuals in the same department. This is done according to binaries (couples) of comparisons and knowing who is better, and by gathering these comparisons, it would be possible to know the ordering of the employees descendingly according to their general performance and according to the comparisons that have been done.( Sawaf,1992)

\section{Compulsory Distribution:-}

In this method each manager is obliged (relatively) to distribute his subordinates on degrees of efficiency scale which is determined by the institution, and this methods takes the so called Normal Distribution, and this is a distribution that sees the majority of people are under median of the scale, and rate of it would decrease whenever we go far from this median scale whether wego up or down.( Abbas,2003)

\section{Management by Objective:-}

- This method depends on the idea of that lessons are in the results, which means that the manager would not pay attention to behavior of the subordinates and their qualities, but he will only care about what they have achieved, and this method goes under the following steps:(Tawazi,2015)

- The objectives (results) that should be achieved are determined, by which the performance would be evaluated based on them. Usually the manager and the employees agrees on these objectives and the timeframe to achieve these goals is also settled.

- 2.During conducting it this method, the manager has to help the subordinates in achieving the objectives, and he has also to follow up on the process of achieving them, and this is for example to know if there is any latency that is out of the subordinate control.

- 3.When the agreed timeframe is over or when it is the time for performance evaluation, the real done results are being compared with what was agreed on, and determining oddities of the whether it was positive or negative.

\section{Checklist:-}

These checklist are being made by a cooperation with the human resources and the direct managers. These checklists explains many aspects of the subordinates behavior in their work, and the attributes they should have, and those are being listed, and the administration should explain the importance of each element on his performance for the job , each element and attribute is being listed in front of him according to its importance, and the manager wouldn't be aware of them, only the HR manager knows them , and when submitting these list to the manager to evaluate the subordinates it will not be mentioned and this is to avoid any biases. The manager also should determine the attributes that the subordinates should have by putting a tick for example, and once the lists are being returned to the manager of HR, and while he is checking the value of the elements he puts each corresponding value for each element in the subordinate's performance by putting a tick.( Mari,2001)

\section{The Degree 360:-}

In this method performance evaluation by all those who are interested, and by many ways and times simultaneously, which is done by the manager, colleagues and subordinates and by using many ways such as checklists , management by objectives, in addition to that it is only done by the end of the year but also continuously ( monthly) and whenever needed. This method is characterized that it provides permanent and full information and from many aspects and all the times, which makes it of good use. But its main drawback is that many people intercept it mainly 
by the managers who are being evaluated by their subordinates, also it acquires all pervious methods of employee's proficiency.( Gad El Rab,2009)

\section{And we can infer the below characteristics:}

* The majority of those methods depend on the authority that the supervisor has hence it is authoritarian, and according to this it doesn't take physiological and social factors into consideration of the employees which affects their proficiency.

* That Methods mostly is known by punitive manner, in other words it makes a direct threat for the employee's safety and his performance stability or it can affect his position.

* As a result for the defects and difficulties that surrounds proficiency measure; it is not usually of administration interest, so it can be described as it is shallow.

* Another aspect is that it is complicated due to the long lists of attributes and characteristics that should be studied out, and the complexity if evaluation systems such as the obligatory selection.

\section{Barriers of Measurement and Performance Evaluation of the Employees:-}

There might be some hard situation during the evaluation, hence it should be expected and to face the employee fairly. It is important to make sure that all notes are objectives and built on realities and not on personal opinions, by then the employee would understand the main basics in evaluation and be assured that the notes are fair and only related to the job tasks. According to there are many barriers and difficulty face the process of measurement and evaluation of the employee's performance, ones related to the evaluator and others to the institution, and they are as follows:

First, Self-Problems and it is divided to:- (Jibreel ,2009)

* Evaluator Characteristics: This problem is related to the characteristics of the evaluator directly or indirectly.

* Indulgence and Leniency: Some evaluators tend to be lenient with employees which is reflected on the results of the evaluation negatively, and would make the process lose its main goal, for example to have equal results for all of those who are being evaluated.

* TheHalo Effect: Thus problem appears because the evaluator might be affected with some of the characteristics of the person who is being evaluated which would make the results appeared not according to what it was meant to be.

* The Central Tendency: and it is also called the tendency toward the center, and it appears due to the tendency of the evaluator to issue general and averageprovisions toward those who are being evaluated without a remarkable distinction.

* Fundamentalism and Modernity: This problem appears with measurement and evaluation processes that is extended to long times, as the evaluator depends on the initial performance of the individual without taking into consideration subsequent developments to the beginning of the evaluation process.

* Personal bias: This problem appears due to the bias of the evaluator to the person being evaluated because of many reasons such as kinship, friendship, gender, homeland and others that make the measurement and evaluation process far from objectivity.

Second, Objective Problems (.Hiti,2003):-

* Not being clear in determining the goals of the evaluation. The institution might be mistaken in determining the main goal of the evaluation and hence the process becomes just a waste of time and money.

* 2.Badly choosing the criteria of evaluation, and this problem appears because the institution won't be able to understand the purposes of the self or object criterion, and such an issue makes the institution loses the opportunity to invest the goals of the measurement and evaluation process.

- Badly choosing the evaluation procedures, which means the inability of the institution to distinguish between the contents of the process of measurement, evaluation and assessment.

* Mis-choosing the timing of the evaluation, as it is known institution varies in the number of times of performance evaluation.

* Imprecision in observing employees' performance, or crediting imprecise criteria in conduction performance comparison or mis-determining its trends.

In view of the above, the institution that wants to limit the barriers and problems that it might face during the process of evaluation, it has to design performance evaluation just as below.( Abu Sheikha,2004)

* Clarity of the goals of the process of performance evaluation. 
* The correct timing of the process

* Validity and reliability of evaluation criteria.

* Accuracy of the credited information with objectives.

* Proportionality of the evaluation method with the objectives.

* The qualification of evaluator.

To gain a successful performance evaluation process, achieving the objectives would return with benefits on the institution and the employee, it is necessary to have some conditions and needed requirements that are related to the procedures and methods of performance evaluation. And some of these conditions are the below:( Shawish,2005)

* Setting rates of performance according to the previous experiences and the actual reality of similar institution.

* Performance rates or criteria should be instruments that help in stirring motivation of the individuals and creating incentives for them to improve and increase their productivity.

* Coordination and cooperation with different levels of administration in the institution while choosing the adequate method of evaluation, criteria and measurements for that method.

* Determining evaluation samples and forms and what it involves of information clearly that enables the supervisor or the evaluator to use it easily.

* Having the direct manager conducting the evaluation process.

* To have all employees whatever were their job level to be subjected to the performance evaluation.

* Informing the employees with the results of the evaluation and discussing that with them, and giving them all possible chances to express their opinions freely, and help and guide them to improve their abilities and skills.

\section{Results of Performance Evaluation:-}

As a sequence to finishing up the performance evaluation process of the employees and coming up with results. Would certainly affect the employee and his career path negatively or positively.That he might achieve job advantages that contribute to his career advancement directly, or might be susceptible to be questioned and be penalized.And some of these results are the below:

\section{First, Promotion:-}

Promotion means being promoted from a job level to a higher one that has particular requirements which is usually revealed of as a result of employee's evaluation and classifying missions and tasks. Promotion might be to have a salary increment, but this is not necessarily at all times, but there are basics for promotion, and some of it are the below:(Rbayah,2003)

* Seniority: Promotion is being done according to the individual's length of service, where the priority is given to the oldest.

* Proficiency: Where the individual who has more abilities to complete job tasks comparing to others is being promoted.

* Promotion according seniority and proficiency, by mixing them together.

\section{Second, Adjusting Salaries:-}

Salaries are being adjusted as a result for the performance evaluation whether it was done formally or informally, as it has become clear that motivation improved if it was rewards are linked with performance. Hence, to have salary increments successful as a motive to make more efforts, it should be built depending on performance evaluation results.( . Sayrafi,2003)

\section{Third, shifting within the institution:-}

As a result of performance evaluation is to be shifted inside the institution, as advancement is done through shifting and moving from one job level to another when the individual has many abilities which have been extracted from his evolution that are superior the current job requirements and place his in the adequate place to his abilities.( Salem, harosh,2002)

\section{Forth, transferring to another job:-}

Evaluation results might increase the burdens and requirements of the jobs and creating new conditions, which means that it requires more knowledge and skills along with the current ones which the current employee doesn't fit anymore as his performance is insufficient, hence they are being transferred to another positions that suits their abilities.( Hassan,2000) 
Fifth, blocking the increment and ending the service:-

Sometimes depriving the employee from his annual increment is a result for the performance evaluation for one year or more according to the performance reports that he gets, which would be with a low or average level. And sometimes, the management resorts to ending the employee's service if his performance was weak and happened for more than one time and it hasn't been fixed or he didn't improve his performance and productivity level.(maher,2014)

\section{Performance Evaluation and Career SecurityAnd Advancement in Jordanian Civil Service System:-}

In different business institution there are red lines that should be crossed out such as job security, which one of the basics of social and community security which leads to more coherence, deeper belonging and desired loyalty. The employee should feel job security be assured regarding his future in the job which his family future lies in so that he would be creative in his performance, and doesn't find himself moved to another job or place that doesn't suit his abilities and qualifications or might lead him to be out of his position. When the employee doesn't know when he will be retired regardless of having suitable age of retiring due to having some exceptions in the system such as retiring and assignment on early Security enables the manager to end his service in an early age without his desire and knowledge - and others who are older and have less proficiency might still be working- in an early age as a result to settlements or positions conflicts that considers his as a threat if he kept on working or for reasons that won't be convincing at all .And also jobs with contracts despite having what justifies it, it is inconsistent with principles of feeling job security and stability. The problem of lacking job security should be treated institutionally if we want the administration to be improved as it is one of the most important barriers of advancement and creativity, and a reason of depression that employees might have. The institution must allow those who are proficient and experienced to be promoted and makes them feel safe and stable. The fall back in job security is considered to be important factors for the phenomenon of sagging and administrative corruption.

\section{The Civil Service System NO.82 for 2013 and its amendments has been issued:-}

According to the item NO.120 of the Constitution, and it has included 19 chapters containing 191 items, and a whole chapter for performance management was given, included 7 items with their branches, and another chapter for ending the service included 12 items with their branches, and a chapter for promotion included 13 items with their branches. The last substantial amendment was made on the system on $14^{\text {th }}$ of February 2016 in which the Prime Ministry allowed the Ministry of Awqaf and Islamic Affairs and Holy Places to send its employees as a scholarship to get the first university degree.

\section{First- Performance Management and Evaluation Instructions:-}

The Civil Service Council has issued performance management and evaluation instruction according to item NO.71/A of the system to be executed on starting from the first of January 2015, and the instruction was applied on the concerned employees with permeant and contact jobs, and job occupants of the second group of the highest group were excluded due to applying the evaluation system of senior leadership positions that is issued the Prime Ministry.

The items included a number of instructions that have organized the evaluation process, and the researcher has summarized it as below:

* The annual performance evaluation samples (Annual performance record and report) that is prepared by the Bureau has been credited for employee's performance evaluation purposes.

* The direct manager with cooperation with the concerned manager determines together the goals of the organizational unit that the subordinate contributes to achieve going along with the credited strategic plan goals.

- The direct manager with a cooperation with his subordinates determine the indicator/results of performance that should be done by the subordinate by the beginning of the year according to the settled organizational goals of the unit, with also stating numbers of performance indicators, and determining the maximum grade for the indicator according to its importance for the organizational unit goals.

* The direct manager should inform the employee about the goals and indicators that are credited in the annual performance evaluation sample and that should be done by him, in addition to the elements of performance evaluation (General and special elements and the maximum grade for the indicator) for each one of it, that according to it the employee's performance and behavior will be evaluated.

* The Human resources unit should distribute copies of annual performance evaluation samples (Annual performance record and report) which has been prepared by the Bureau to all the department units and directorates. 
* The direct manager should follow up continuously and review periodically the employees' achievements and level of performance that the he has to achieve, with them, which should go along with the credited goals that have been agreed on by the beginning of the year, and writing down personal notes in the annual performance evaluation sample once each 5 months.

* Observing strength points in the employees' performance and reinforce them, and the weakness points as well and how to fix it, or making any necessarily modifications according to the goals or indicators or both of them.

* The direct manage and the employee should sign out the performance record after each revision and should be submitted to the concerned manager to have it accredited, and the General Security or who is authorized by him should check the integrity, objectivity and accuracy of performance evaluation organization.

* Annual performance evaluation samples are used for the employees who are under probation period, according to the nature of the job and the special activity taking into account the continuity of observation process, and also following the his performance, and the evaluator can end his service at any level of the evaluation levels according to the results of his performance and according to the placement of the General Security which is based on the placement of both of the direct manager and the concern and manager.

* Any dereliction of the direct and concerned managers is taken into consideration, if they didn't stick out to organize annual performance evaluation samples to their subordinates, and the General Security has to draw their attention, and penalize them according to the system, as the proficiency and objectivity of performance and evaluation management is reflected on the performance evaluation of the direct and concerned managers as one of their evaluation standards.

* The concerned manager is responsible for evaluation the direct manager, and stating his opinion in the specified block for that, and submit it to the General Manager and who is authorized, and mentioning reasons in cases of disapproval, and the General Security or who is authorized credit the grade and the final mark for the employee's annual performance, and the employee who gets a law or average grade has the right to object on it within3 days starting from the next day of getting the report.

* The objection commission looks into the employees objects that has been submitted to it by the General Security or who is authorized during 7 days starting from the next day of getting them, and the department sends to the Bureau a signed list by the department General Security, includes employees names, categories, grades and rates by a deadline of December of each Year.

* The annual performance evaluation report should be conditional unless the rate was average or law the employee should have a look on it. All employee have the right to look at their results (final rates) for their annual performance by their department after one month of depositing lists of annual performance evaluation to the Bureau.

- Procedure and decisions that came out as a result of the annual reports as stipulated in item NO. 75 of the Civil Service System should be taken, after they acquire the final status.

In addition to the pervious procedures and instruction of performance management and evaluation, the Bureau has issued a guide of performance indicators in the Civil Service - which is considered as a reference in performance evaluation that is fair and objective if it was taken seriously -within a strategic plan by setting projects to invest the general job headed by the developmental project and updating the models and instructions of performance evaluation, describing and classifying positions to be an objective measurement tool by linking the individual performance with the organizational performance and upgrading the proficiency and effectiveness of the governmental performance, which enables the direct manager to evaluated his subordinates objectively and neutrally, and also finding out basics for granting rewards and incentives. This Guide was done by a specialized team from both general and privet sectors under the Bureau umbrella.

\section{Second- Career Advancement and Security in the Civil Service System:-}

The laws that govern employees of the Civil Service forms the basis that by it career advancement and security can be achieved, which make the employee feels high levels of tranquility regarding his present and future, and make away from any sources for physiological anxiety that frustrate his productivity, and enables him to do his tasks responsibilities in best ways, which gives a bright image of the distinguished governmental performance.

And here it is important to maintain job security and stability to increase the proficiency and effectiveness of the Civil Service employees, and expanding their productivity and ennobling their ethics and behaviors, and also open the way to the creative proficient people administratively and technically. And this leads as to the following inquiry: 
Has the Civil Service System that is currently used, and the performance management and evaluation that is issued according to it contributed to figuring out the strength and weakness points and achieving more and more of career security and advancement?

At the beginning, I want to confirm that career security and stability lies in applying legalization texts fairly and objectively, and not by the inefficiency of the legalizations, as legalization lies in making any modification whenever needed. However it is hard to eliminate moodiness in executing the provisions. And as it is known the issue of career security is relative, for example a procedure might be considered as a career security to one employee, can be also considered as a threat to another employee who will feel injustice by taking others his rights, many people see that those who call for job security are the employees who are sluggish and don't seek to improve their selves and their skills and experiences.

And by reading the items of Civil Service System that are related to career security and advancement, the research cites the below notes:

The Civil Service System has cancelled the permanent jobs starting from the First of January 2014 , and employment now depends on vacancies in the Civil Service according to annual contacts renews annually according to the efficacy of the employee and this - according to the opinion of the majority of the employees and their associations- will take the career security off, and would negatively affective the career security that guarantees that the employees stays in his job, and waning the possibility of ending his services, and also make the employee's thoughts restricted only in one question, will he remains in the position or no ?

Also, the employee can be under many orders by managers for their own interests and his own good, as the employee's future is in hand of his managers, and he may be assigned to job that doesn't suit his academic qualifications and pervious experiences - despite having instruction to describe and classify positions and conditions of employment-. This is actually there any many governmental departments, as you can find an accountant who has Political Sciences or History degree for example, and you can also find a Legislation Officer or International Relations Officer who's their majors don't have anything to do with their position nature, you might also find an Information officer that his qualifications are related to Financial or Health Management, health or Psychological Guidance and so on , and it is unfair to ask him for creativity and achievements.

From another side, employment based on annual contract would contribute to make those who are proficient and experience leave working with the general service by the first chance they get, and to overcome this gab in the system, I suggest to make the probation period between 2-3 years in which the employee practice tasks that go along with his qualifications and experiences, and to determine his career fate by a specialized committee include one member of the Bureau that makes an interview and a test that is related to his job area, and depending on the results, it will be decided whether he will stay or leave.

The System stated the disciplinary actions that would be taken with the employee after the performance reports are finalized, and it would be as below:

- If it appears that the mentioned rate in the annual performance report is average, his attention will be paid in a written manner, and he will be asked to fix the aspects of negation and to improve his performance level.

- If his rate in the annual performance report was weak for one year only or average for two consecutive years, then he will be deprived from one annual increment.

- If his rate in the annual performance report was weak and the previous year was average, he will be deprived from annual increment for three consecutive years.

- If his rate in the annual performance report was weak for two consecutive years his services will be ended according to a decision made by the specialized person in charge.

- All sanctions that is done to an employee throughout the year have been taken into consideration, as an employee cannot take more than a good rating if he was subjected to a particular sanction which is texted within the articles between (2-6) from the item NO.141/A from the system.

In the light of the above mentioned disciplinary actions which is one right of the management rights that it can execute toward the negligent employee aiming to achieve effective supervision upon the employee's performance and immunize him from making mistakes whether intentionally or not, and to achieve highest degrees of justice among employee, I strongly agree and support it if the below was done: 
First: It is not occupied excesses by those who are in charge of the general job, who intends to take revenge and get rid of proficient employees and replace them with those of kinship, and not to have justice and equality absent, and not to have the management predominated by nepotism, cronyism and regionalism.

Second: Protecting the employee from injustice and abuse by skipping him in promotions. As an annual malicious report with very good rating to a hardworking and loyal employee by his manager is enough to deprive him from the permissible promotion that requires excellent rating for the two previous years, and nominating another employee who doesn't acquire proficiency and experience to get the permissible promotion and exceed him with one degree, and the employee doesn't have to object on a very good annual performance rating at all-or moving to early retirement or arbitrarily shifting-.

Third: To study out the reasons of career illnesses anddetermine tools and precautionary and therapeutic measures for them by efficient and experienced employees who are known with integrity, Affiliation, loyalty and career neutrality.

- The basics of promotion and modifying the current conditions, and promotion to supervisory and leadership jobs are enough to motivate employees and encourages them to improve their performance, and activating the principle of completion among. them , if these basics where fairly, transparently and objectively applied, as the system grants the ideal employee 5 annual increments in addition to granting him distinction increment that equals two annual increments for an employee who has got excellent rating in two consecutive years, and it also granted the employee who patented an invention five annual increments, and two annual increments to those who publish a scientific research in addition to permissible promotion, where it has been allowed to promote the employee ( of the first level and less) who has been for three actual years of service of his performance level for the last two years was excellent rating, and it has been also allowed to promote to the special level if he spent five actual years in the first level and his performance report rating was excellent for the last two years.

And Personally I have two notes on the basics of promotion and they are:

- It has disregard involving the employee who has been intended to promote him permissibly in training programs, and this was a condition in the obligatory promotion. The origin here is to subject him to more training hours as it was done previously to compensate the difference of experience by level.

- The MA degree was equalized to the BHD degree in regard to the numbers of annual granted increments for the employee who gets them, and the priority should be to the behalf of those who get BHD.

- The instructions of performance management and evaluation have include a number of items that has the ability to detect the strength and weakness points in the employee's performance, and it has organized the evaluation process as well.

\section{Results:-}

* It has been figured out that the instructions of the performance management and evaluation is capable of figuring out strength and weakness points in employees' performance, and to achieve justice and equality among them, as well as meeting their training needs if it was applied fairly and objectively.

* The guide of performance indicators in the Civil Service for 2014 which was done by a specialized team from both general and privet sectors under the Bureau umbrella which is considered to be a reference in performance evaluation that is fair and objective if it was taken seriously.

* The basics of promotion and modifying the current conditions, and promotion to supervisory and leadership jobs are enough to motivate employees and encourages them to improve their performance, and activating the principle of completion among. Them, if these basics where fairly,transparently and objectively applied.

* The Civil Service System NO.82 for 2014 and its amendments, despite of some simple gaps that can be easily overcome, is capable of establishing career security among employees.

\section{Recommendations:-}

* Evaluating employee's performance and achievements regardless their levels and job titles objectively and professionally, and to apply reward and punishment approach among all fairly and with no exceptions, reaching to have employees who feels safe and secure where principles of loyalty and affiliation to their jobs will be rooted and entrenched both managers and subordinates. 
* Activating the role of liaison officers and Civil Service Bureau representatives who are available in all the governmental, and to choose who are efficient and experienced to address evil job illnesses which abuse out governmental institutions that are nepotism, cronyism and regionalism, skipping in promotions and abuses in shifting and employment in supervisory positions, and all other influences and effects of the job by all its different types and forms.

* Applying general work ethics and behaviors, and penalize harshly all of those who cross the redlines and commit mistakes toward the employees.

* 4.Reveiwing the decisions of employment according to an annual contract that is annually renews that is applied currently in the Civil Service System NO.82 for 2013 as keeping it will effect negatively on career security in all aspects that has been mentioned previously if that hasn't been accompanied with corrective action.

\section{References:-}

1. Civil Service system NO82 for 2013 and its amendments till $16^{\text {th }}$ of October 2014.

2. Performance evaluation management instruction for 2015 that is issued according to item NO.71/A of the System.

3. The Guide of Performance Indicators in the Civil Service for 2014.

4. Abbas, Suhaila Hassan, human resource management, strategic entrance, Dar Wael for Publishing and Distribution, the first edition, Oman 2003.

5. AbdAlBaqi, Salah Al Dinn and others, Administration of HR, Alexandria: Alexandria University, The new university office talking 2007.

6. Abdel-Mohsen, Mohammed Tawfiq, performance assessment (new entrances to the New World,(Arab House for Publishing and Printing, Beirut 2013.

7. Abu Sheikha, Nadir, evaluate the performance of employees in government agencies in the Arab countries, the Arab Organization for Administrative Sciences, Cairo 2000.

8. Abu Sheikha, Nadir, recognize employees for objective evaluation of their performance over the system and its relationship to some personal and functional characteristics, applied study on government agencies, Journal of Public Administration, Vol. 45, No. 4.2004.

9. Adel Hassan, the administration in the government sector, Arab Renaissance Publishing House Printing and Publishing, Beirut, 1985.

10. Al-Hamoud, Ahmed Hammad, job performance evaluation, roads, information, alternatives, Institute of Public Administration, Vol. 34, No. 2, Riyadh, 1994.

11. Al Hiti, Khalid Abdul Rahim, Human Resource Management, Dar Wael for Publishing and Distribution, Amman2003.

12. Al Salem, muaedsaeed, and Hrosh, salehaddel, human resources management, the modern world for the publication and distribution of books, Oman 2002.

13. Al Sawaf, Mohammed Maher, evaluating job performance in public administration, the Institute of Public Administration, Riyadh, 1992

14. Al Sayrafi Mohammed, Human Resource Management, Dar curricula for publication and distribution, i 1, Oman 2003.

15. Al Sideeq, Mansour Busnineh, Al Farsi, and Suleiman, Human Resources: its importance, organization, responsibilities, and tasks, Tripoli: Academy of Graduate Studies 2015.

16. Assaf, Abdul Muti, recent trends to evaluate the performance of employees in state administration, Journal of Social Sciences, Kuwait University, 16 volumes, No. 1.1998.

17. Gad El Rab, Sayed Mohammad, indicators and criteria to measure and evaluate the performance, strategic entrance to the continuous improvement and competitive differentiation, Dar Arab Thought, 1st Floor, Cairo 2009.

18. Hamzawy, Mohamed Sayed, human resources management in government agencies, Dar University, Riyadh, 1987.

19. Hanna, Nasrallah, Human Resource Management, Dar Zahran for Publishing and Distribution, Amman 2001.

20. Hassan, Mohammed raweah, Human Resource Management, University House Publishing, printing and distribution, Alexandria 2000. 
21. Ismail, Nora Hani, assess the human resources department and the extent of his contribution to raising the general performance of enterprises, Research Master, Tishreen University, Faculty of Economics, Damascus 2005.

22. Jibreel, Weal Mohammad, Teachers Performance Evaluation, a published research, Arab Forum for Human Resource Management 2009.

23. Mari, Mohammed Maree, the evaluation system in the institutions and departments guide, a series satisfaction of information, Dar satisfaction for publication, i 1, Damascus 2001.

24. Mustafa, Syed Ahmed, human resource management, modern management ofintellectual capital, the AngloEgyptian Library, Cairo, 2004.

25. Rbayah, Ali Mohamed, human resource management, Dar Al Safa for Publishing and Distribution, Amman 2003.

26. Rozlev, Mehdi Hasan, and Qatamin, Ahmed, Administrative Control (Quantitative Approach), Dar nostalgia, Oman, 1995.

27. Shawish, Mustafa, Human Resource Management, Sunrise House, 3rd floor, Oman2005.

28. Evaluation of employees in small and medium institutions, Tawazi for Human Resources 2015. http://jordan.smetoolkit.org/jordan/ar/content/ar/56515

29. Maher, Ahmad, Administration of HR, Alexandria, University House 2014. http://www.hrdiscussion.com/hr6227.html 